\title{
A cell-based assay system for activators of the environmental cell stress response
}

Jennifer A. Harbottle ${ }^{1}$, Linda Petrie ${ }^{1}$, Madeleine Ruhe ${ }^{1}$, Wael E. Houssen ${ }^{2,3}$, Marcel Jaspars $^{2}$ \& Andreas F. Kolb ${ }^{1,4}$

${ }^{1}$ Metabolic Health Group, Obesity \& Metabolic Health Theme, Rowett Institute,

${ }^{2}$ Marine Biodiscovery Centre, Chemistry Department, University of Aberdeen, Aberdeen AB24 3UE, Scotland, UK

${ }^{3}$ Institute of Medical Sciences, University of Aberdeen, Aberdeen AB25 2ZD, Scotland, $U K$

${ }^{4}$ corresponding author Dr Andreas Kolb Metabolic Health Group The Rowett Institute University of Aberdeen Foresterhill Aberdeen

AB25 2ZD

UK

phone: 0044-1224-438645

e-mail: a.kolb@abdn.ac.uk

Abbreviations:

SFN: sulforaphane

MBC: Marine Biodiscovery Centre

CUR: Curcumin

CTB: Cell Titer Blue

ARE: antioxidant response element;

INS: insulator;

NQO1: NAD(P)H:quinone oxidoreductase 1.

Keywords: cell-based assay, NQO1, phytochemical, anti-oxidant, Nrf2 


\begin{abstract}
Improved health span and lifespan extension in a wide phylogenetic range of species is associated with the induction of the environmental cell stress response through a signalling pathway regulated by the transcription factor Nrf2. Phytochemicals which stimulate this response may form part of therapeutic interventions which stimulate endogenous cytoprotective mechanisms, thereby delaying the onset of age-related diseases and promoting healthy ageing in humans. In order to identify compounds that activate the Nrf2 pathway, a cell-based reporter system was established in HepG2 cells using a luciferase reporter gene under the control of the Nqo1 promoter. Sulforaphane, an isothiocyanate derived from cruciferous vegetables and a known activator of the Nrf2 pathway, was used to validate the reporter system. The transfected cell line HepG2 C1 was subsequently used to screen natural product libraries. Five compounds were identified as activating the bioluminescent reporter by greater than 5 -fold. The two most potent compounds, MBC20 and MBC37, were further characterised and shown to stimulate endogenous cytoprotective gene and protein expression. The bioluminescent reporter system will allow rapid, in vitro identification of novel compounds that have the potential to improve health span through activation of the environmental stress response.
\end{abstract}




\section{Introduction}

The molecular mechanisms underlying the ageing process are complex $[1,2]$. Reactive oxygen species (ROS) and accumulation of oxidative lesions are implicated in the pathogenesis of many age-related diseases and in determining lifespan $[3,4]$. Therefore cells have developed protective mechanisms to maintain cellular homeostasis in the face of exogenous or endogenous challenges $[5,6]$. The environmental cell stress response (ESR), driven by the transcription factor nuclear factor (erythroid-derived 2)-like 2 (Nrf2), provides endogenous antioxidant defence to maintain intracellular redox balance [7]. Under basal conditions, where the intracellular environment is in a reduced state, the redox sensor Kelch-like ECHassociated protein 1 (Keap1) sequesters Nrf2 in the cytoplasm and targets it for ubiquitination and degradation, thereby repressing its transcriptional activity. Keap 1 is inactivated by electrophilic or oxidative modification. As a consequence newly synthesised Nrf2 escapes Keap1 binding, is stabilised, and accumulates in the cytoplasm [8]. Nrf2 subsequently translocates to the nucleus where it heterodimerises with small musculoaponeurotic fibrosarcoma (Maf) protein and binds to the $5^{\prime}$-upstream regulatory antioxidant response element (ARE; also known as the electrophile-responsive element, EpRE) [9]. This facilitates transcriptional activation of target genes that encode many antioxidant and Phase II detoxification enzymes, including glutathione-S-transferase (GST), heme oxygenase-1 (HO-1) and $\mathrm{NAD}(\mathrm{P}) \mathrm{H}$ :quinone reductase (NQO1).

The ESR is repressed progressively during aging. Pharmacological or dietary stimulation of Nrf2 signalling is associated with chemopreventive activity and protection against many age-related diseases $[10,11]$. The Nrf2 pathway therefore provides a promising target for enhancing stress resistance, delays the onset of agerelated disease and promotes healthy ageing.

By comparing the global gene expression profiles of wild type and $\mathrm{Nrf2}^{-/}$mice, it has been shown that phytochemicals induce phase II detoxifying enzyme expression via Nrf2 [12-14]. Sulforaphane (SFN), an isothiocyanate derived from cruciferous vegetables, has elicited much attention for its chemopreventive and cytoprotective effects [15]. The electrophilic compound mimics a transient oxidative insult, whereby it reacts with specific cysteine residues on the redox sensor protein Keap1, thus disrupting the association of Keap1 with the Neh2 domain of Nrf2 [16]. This leads to stabilisation and nuclear translocation of Nrf2, thus potent activation of phase II enzyme activity and enhanced stress resistance [17]. However, the poor stability and narrow therapeutic window of SFN limit its use in vivo and it is therefore of interest to identify and characterise alternative compounds that effectively induce the endogenous stress response.

The aim of this study was to develop a cell-based, stable bioluminescent reporter system to determine Nrf2-driven gene activation. Transcriptional regulation of NQO1 is mediated primarily through Nrf2 signalling, thus it has been referred to as "one of the most consistently and robustly inducible genes within its class" [18,19]. NQO1 was therefore considered a prototypical target of Nrf2 and selected as a proxy marker of Nrf2 signalling in this study. Once validated in an established line of human hepatocellular carcinoma HepG2 cells, responsive cell clones were used to 
screen, identify and characterise novel compounds that induce cytoprotective genes in vitro.

\section{Materials and methods}

\subsection{Chemicals}

Sulforaphane (SFN) was obtained from Cayman Chemical Company (in ethanol at a concentration of $10 \mathrm{mg} / \mathrm{ml}$, equivalent to $56 \mathrm{mM}$; \#10496). Curcumin (CUR) was purchased from Axxora (ALX-350-028) and dissolved in DMSO (Hybri-Max, Sigma) at a concentration of $100 \mathrm{mM}$. A natural product library was obtained from the Marine Biodiscovery Centre (MBC), University of Aberdeen. A fraction of the library consisting of 96 compounds mainly comprising flavones, flavonols, flavanones and isoflavones was arrayed on a 96-well plate as single compounds at $20 \mathrm{mM}$ dissolved in DMSO and stored at $-20^{\circ} \mathrm{C}$. The library was screened at a $1: 1,000$ dilution, with a $20 \mu \mathrm{M}$ final concentration of compound ( $0.1 \% \mathrm{v} / \mathrm{v}$ DMSO). Control cells were treated with vehicle at the concentration of the highest concentration of phytochemical used. A second chemical library (phytoquest) was obtained from LifeArc (London, UK). The library consists of around 1200 compounds spread over 1596 -well plates. The compounds were provided at a concentration of $10 \mathrm{mM}$ dissolved in DMSO and were used at a final concentration of $10 \mu \mathrm{M}$ or $5 \mu \mathrm{M}$.

\subsection{Cell culture}

HepG2 cells (ECACC catalogue number 85011430 ) and transfected cell clones were cultured in DMEM (Biosera, cat no LM-D1107) containing 10\% FBS, PenicillinStreptomycin $(100 \mathrm{U} / \mathrm{ml}, 100 \mu \mathrm{g} / \mathrm{ml}), \mathrm{L}$-glutamine $(2 \mathrm{mM})$ and 1\% NEAA (all from GIBCO) at $37^{\circ} \mathrm{C}$ in an atmosphere of $95 \%$ air and $5 \% \mathrm{CO}$. HepG2 cells were stably transfected by electroporation with the plasmids pNQO1-luc (a gift by Professor John Hayes, University of Dundee) [20] and pBK-INS2 [21]. The pNQO1-luc plasmid, schematically represented in suppl. Fig. S3b, carries a $1.1 \mathrm{~kb}$ promoter fragment containing the ARE of the mouse $\mathrm{NAD}(\mathrm{P}) \mathrm{H}$ :quinone oxidoreductase 1 ( $\mathrm{Nqo1}$ ) gene linked to a luciferase reporter gene in the backbone of the plasmid vector $\mathrm{pGL} 3$ (Promega). A mutated version of the NQO1-luc (pNQO1-mut-luc) construct carries a G>T mutation at position 5 of the antioxidant response element (ARE) sequence: CACAGTGAGTCGGCAAAATT. The pBK-INS2 plasmid (suppl. Fig. S3a) contains two copies of the chicken $\beta$-globin insulator element in the backbone of the vector pBKCMV (Stratagene), and a selectable neomycin-phosphotransferase marker gene. Prior to electroporation, pNQO1-luc and pBK-INS2 were linearised by digestion with Notl and Mlul, respectively, and purified by phenol chloroform extraction and ethanol precipitation.

A total of $1 \times 10^{7}$ cells were electroporated in $1 \times$ PBS $(700 \mu l)$ with $5 \mu \mathrm{g}$ pNQO1-luc, 5 $\mu \mathrm{g}$ pBK-INS2 at $250 \mathrm{~V}$ at $950 \mu \mathrm{F}$ using a BioRad electroporator. Cells were selected in medium containing $400 \mu \mathrm{g} / \mathrm{ml} \mathrm{G} 418$ for 2 weeks after which individual cell clones were picked into a 24-well plate and grown up. In order to identify cell clones which are responsive to activators of the environmental cell stress response the cell clones were seeded into two parallel 24-well plates, one of which was exposed to a treatment with $10 \mu \mathrm{M}$ sulforaphane, whereas the other plate was exposed to 
treatment with vehicle (suppl. Fig. S4). Two cell clones were selected from the transfection (A4 and C1) based on their high level of steady state luciferase reporter gene expression and the high levels of inducibility by sulforaphane. Aliquots of the transfected cell clones were frozen down and used for the experiments at passage 412 from time of electroporation.

Transient transfections were done using the GeneJuice reagent according to the manufacturer's recommendations (Merck). Cell viability was typically assessed using the CellTiter-Blue (CTB) assay (Promega) and in some experiment using the MTT assay (Abcam). Both assays are based on measuring reducing compounds in the cell (mainly NADPH) leading to a conversion of resazurin to resurfin (in the case of CTB) or of MTT (3-(4,5-Dimethylthiazol-2-yl)-2,5-diphenyltetrazolium bromidefor) to formazan (in the case of MTT). The major difference between the assays is that formazan is detected in the cell, whereas resurfin is detected in the medium.

\subsection{Proteomics analysis}

Protein for the proteomics analysis was isolated from $90 \%$ dense $10 \mathrm{~cm}$ dishes of HepG2 cells. Cells in the treatment groups were incubated for $24 \mathrm{~h}$ in medium containing $10 \mu \mathrm{M}$ sulforaphane (SFN) or $10 \mu \mathrm{M}$ curcumin (CUR). Control cells were maintained in normal cell culture medium. For each experimental group six $10 \mathrm{~cm}$ cell culture plates were used. An additional plate was used for total RNA isolation to confirm the expected gene expression changes.

After phytochemical treatment, medium was removed, and the dishes were washed with ice cold PBS. 300 $\mu$ l of lysis buffer (1x PBS containing 1\% SDS, 1\% NP-40 and $0.5 \%$ deoxycholic acid) was added to each $10 \mathrm{~cm}$ dish [22]. The cells were detached from the plate using a scraper, transferred to a microcentrifuge tube and homogenised using a small pestle. After incubation on ice for $45 \mathrm{~min}$, the tubes were centrifuged at $13000 \mathrm{~g}$ at $4^{\circ} \mathrm{C}$ for $10 \mathrm{~min}$. The supernatant was transferred into new precooled microcentrifuge tube and stored at $-80^{\circ} \mathrm{C}$.

Protein concentration of the protein extracts was determined by a Bradford assay [23]. Briefly, cell lysates were diluted 1:100 with water and $10 \mu \mathrm{l}$ and $50 \mu \mathrm{l}$ of this dilution were analysed. A protein standard was prepared containing 0 to $5 \mu \mathrm{g}$ of protein in a $50 \mu \mathrm{l}$ volume. The standard was also supplemented with 1:100 volume of lysis buffer. Standard and samples were measured in triplicate and duplicate, respectively. $200 \mu \mathrm{l}$ of Bradford reagent was added to the $50 \mu \mathrm{l}$ of samples/standard. After an incubation of $5 \mathrm{~min}$., the OD was read at a wavelength of $595 \mathrm{~nm}$ in a photometer.

The protein lysate was diluted to a concentration of $600 \mu \mathrm{g}$ in $300 \mu \mathrm{l}$ lysis buffer and precipitated by addition of $100 \mu \mathrm{l}$ TCA containing $80 \mathrm{mM}$ DTT. The samples were incubated $1 \mathrm{~h}$ at $4^{\circ} \mathrm{C}$, to allow the protein to precipitate completely. Samples were centrifuged at $10000 \mathrm{~g}$ for $10 \mathrm{~min}$. at $4^{\circ} \mathrm{C}$. The supernatant was discarded, and the pellet was washed 4 times with $1 \mathrm{ml}$ of ice-cold acetone containing $20 \mathrm{mM}$ DTT and dried. Two dimensional SDS-PAGE analysis was carried out at the Proteomics unit of the Rowett Institute using established protocols as described previously [24-27]. The gels were analysed using the Bio-Rad PDQuest software. Protein spots identified as significantly changed (t-test, 95\% confidence interval) were excised from the gels using a robotic spot cutter (BioRad). Following trypsin digestion, protein identities were determined by mass spectrometry using either MALDI-TOF (Voyager-DE PRO, 
Applied Biosystems, Warrington, Cheshire, UK) or LC/MS/MS (Q-trap Applied Biosystems). The mass spectra were corrected for isotope abundance, and the resulting peptide mass list profiles were analysed using the Matrix Science 'Mascot' web tool (http://www.matrixscience.com). Proteins which were identified with a score of more than 100 and coverage of more than 3 peptides were considered for further analysis. The data of the mass spectrometric analysis was further validated by comparing the predicted molecular weight of the identified protein with the molecular weight observed in the gel.

\subsection{Luciferase activity assay}

Luciferase activity was measured in cytoplasmic extracts as described [28]. Briefly cells were washed twice with 1x PBS, and a lysis buffer (25mM KPO4 pH 7.8, $8 \mathrm{mM}$ $\mathrm{MgCl}_{2}, 1 \mathrm{mM}$ EDTA, 1\% Triton X-100, 15\% glycerol, 1mM DTT, broad spectrum proteinase inhibitor mix [SIGMA P-8340]) was added to the cells. 100ul of lysis buffer per well was added to 96 well plates. The plates were shaken at $600 \mathrm{rpm}$ for $5 \mathrm{~min}$ and exposed to a freeze thaw cycle. $50 \mu \mathrm{l}$ of the cytoplasmic extracts were transferred directly to a white 96-well plate for measurement. In a 24-well format, cells were lysed in 150ul per well. The lysate was spun in a microcentrifuge for $1 \mathrm{~min}$. at $10000 \mathrm{~g}$ at $4^{\circ} \mathrm{C}$. The cytosolic supernatant $(150 \mu \mathrm{l})$ was transferred to a fresh tube. $50 \mu \mathrm{l}$ of the cytoplasmic extract were used for the measurement. Luciferase activity was measured using Microplate Luminometer (EG\&G Berthold) after addition of a

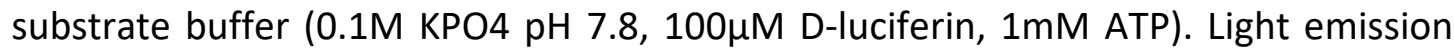
was recorded for $5 \mathrm{sec}$. and the area under the curve was determined using WinGlow (EG\&G Berthold) software. The remaining cytoplasmic extract was saved for protein analysis and stored at $-80^{\circ} \mathrm{C}$.

\subsection{Western Blot analysis}

$30 \mu \mathrm{l}$ of cytoplasmic extracts was mixed with a $10 \mu \mathrm{l}$ of a $4 \mathrm{x}$ protein sample buffer (40\% glycerol, 0.24M Tris/HCl pH 6.8, 8\% SDS, 0.2M DTT, 0.04\% Bromophenol blue) and denatured by incubation at $95^{\circ} \mathrm{C}$ for 5 minutes. The samples were separated on a $10 \%$ SDS-polyacrylamide gel, transferred to a $0.2 \mu \mathrm{m}$ nitrocellulose membrane via semi-dry electrophoretic transfer, and blocked overnight with 3\% skimmed milk protein in Tris-buffered saline-0.1\% Tween 20 (1x TBST) buffer. Blots were incubated at room temperature for $3 \mathrm{~h}$ with specific primary monoclonal antibodies, anti-NQO1 (AB10239, Calbiochem, used at 1:200 dilution), anti-AKR1B10 (ST1507, Calbiochem, used at 1:1,000) or anti- $\beta$-actin (A5441, Sigma, used at 1:10,000). Membranes were washed $3 \times 10$ min with $1 \times$ TBST, incubated with appropriate horseradish peroxidase (HRP)-conjugated secondary antibodies (\#7076, Cell Signalling Technology, used at $1: 1,000)$ and washed again $3 \times 10$ min with $1 \times$ TBST. Proteins were detected by enhanced chemiluminescence using Pierce Super Signal reagents. Chemiluminescence was detected using a Fuji Imaging system and quantified using Advanced Image Data Analyser software (Aida/2D Densitometry).

\subsection{RNA analysis}

RNA was isolated from cells using TRI-reagent (Sigma) following the manufacturer's instructions. Reverse transcription of RNA was done with MLV RNAse (-) reverse transcriptase (Promega) following the supplier's recommendations. $2 \mu \mathrm{g}$ of total RNA 
was used as template for the cDNA synthesis reaction. A 1:10 dilution of the reaction was subsequently used as template for quantitative PCR using a SYBR green reagent (Applied Biosystems 7500 Fast System).

Quantitative PCR amplifications were done with a final primer concentration of $0.5 \mu \mathrm{M}$. Primer design was done using Primer Blast [29]. The sequences, annealing temperatures and amplicon sizes of the oligonucleotides used in this study are provided in table 1 . The PCR products obtained by quantitative PCR were evaluated by melting point analysis and agarose gel electrophoresis. Amplifications were done at 40 cycles of $15 \mathrm{~s}$ at $95^{\circ} \mathrm{C}, 15 \mathrm{~s}$ at the indicated annealing temperature and $30 \mathrm{~s}$ at $72^{\circ} \mathrm{C}$. Data were collected at the end of each PCR cycle. Standard curves for all genes were generated from serial dilutions of a plasmid containing the cDNA for each gene. The crossing points obtained from the sample analysis was then correlated with the standard curves to provide a concentration of the individual PCR product. Expression of the casein genes was then correlated with expression of the reference gene $\beta$ actin in the same sample (expressed as pg of gene per pg of reference).

\subsection{Statistical analysis}

Between three and six independent experiments, each performed in triplicate, were used to validate the pNQO1-luc reporter model with SFN and to confirm induction of the stress response by $\mathrm{MBC} 20$ and $\mathrm{MBC} 37$. Data are presented as means and standard error of the mean (SEM) and analysed using independent samples student t-test or one-way ANOVA with post-hoc Bonferroni, as appropriate. Statistical analysis was conducted using IBM SPSS Statistics software, Version 24. A p-value below 0.05 was considered statistically significant.

\section{Results}

The objective of the experiments presented in here was to develop a cell based assay system for the identification of chemicals from natural product libraries which can activate the protective environmental cell stress response (ESR) pathway. Activation of this pathway, mainly regulated by the transcription factor Nrf2, is observed in (1) long-lived animals from yeast to mammals and (2) in response to a diet rich in fruit and vegetables [2,30]. Chemicals which combine a strong activation of the ESR response with a low inherent toxicity may provide leads for novel antiaging agents. We therefore set out to develop cell based assay systems to identify novel natural chemicals which fulfil these criteria. The first target cell type chosen was the human liver cell line HepG2 representing the organ which plays the major role in mammalian detoxification processes.

\subsection{HepG2 cell viability in response to phytochemical treatment}

Two well characterised phytochemicals, sulforaphane (SFN) and curcumin (CUR) (Fig. 1) were chosen as substances to identify and validate the reporter cell lines. As a first step the toxicity of SFN and CUR in HepG2 cells was assessed (Fig. 1c and d). The cells were exposed to concentrations of $5,10,25$ and $50 \mu \mathrm{M}$ for 24,48 and $72 \mathrm{~h}$. Cell viability was measured using the Cell Titre Blu reagent (Promega), which allows the quantification of the conversion of the redox dye resazurin into a fluorescent end 
product (resorufin). The data shown in Fig. 1 demonstrate that a $5 \mu \mathrm{M}$ concentration of both chemicals is well tolerated for an incubation period of $72 \mathrm{~h}$ and a concentration of $10 \mu \mathrm{M}$ is well tolerated for a period of $24 \mathrm{~h}$ (Fig. 1). Analysis of cell viability using the MTT method (suppl. Fig. S1) shows a similar concentration dependent toxicity of SFN and CUR in HepG2 cells.

\subsection{Characterisation of proteome changes induced by phytochemical treatment}

Phase II enzymes are key components of the environmental cell stress response. In order to identify additional marker proteins for the environmental cell stress response, the global protein response to SFN and CUR treatment was analysed using 2D gel electrophoresis and mass spectrometry. Total cell protein was isolated from HepG2 cells incubated with $10 \mu \mathrm{M}$ SFN or $10 \mu \mathrm{M}$ CUR for $24 \mathrm{~h}(\mathrm{n}=6)$. Using the PDQuest software (Bio-Rad) a total of 11 proteins were found to be changed in response to both, sulforaphane and curcumin. The spots were identified as significantly changed using a t-test with $95 \%$ confidence interval. A further 9 protein spots were found to be changed only in the SFN treated cells. The protein spots found changed in both treatment groups were excised and analysed by mass spectrometry (table 2, suppl. Fig. S2a). However, only expression of three of the genes identified (aldo-keto-reductases 1B10, 1C1 and 1C2) could be verified by qPCR (suppl. Fig. S2b). This is consistent with a re-analysis of the densitometric spot signals using ANOVA (suppl. Fig. S2a) in which only one of the 11 changes induced by curcumin originally identified by the t-test could be confirmed as significant ( 8 of 11 protein expression changes were confirmed for the SFN treatment group). AKR1B10 and AKR1C1 and their corresponding RNAs were used alongside the established phase II response genes NQO1 and HMOX1 to characterise the environmental cell stress response in reporter cells. Other proteins which showed significant changes at the level of protein may have been detected due to mechanisms which are mediated at the post-transcriptional level (e.g. by changes translational efficiency by microRNAs, or changes by protein modification).

\subsection{Generation and identification of reporter cell lines}

To establish a HepG2 cell based assay system a $1.1 \mathrm{~kb}$ mouse NQO1 promoter element linked to a luciferase reporter gene (pNQO1-luc, a gift from Prof John Hayes, University of Dundee, suppl. Fig. S3) [20] was co-transfected into HepG2 cells together with the plasmid pBK-INS2 [21] (derived from the plasmid pJC13-1, a gift from Prof. Gary Felsenfeld, NIH, Bethesda), which contains two copies of the chicken $\beta$-globin insulator sequence and a neomycin selection marker gene expression cassette. The insulator elements are expected to stabilise the expression of the reporter gene [31]. As a control a plasmid carrying the NQO1 promoter carrying a mutated anti-oxidant response element [20] was transfected (again together with the pBK-INS2 plasmid).

HepG2 cells were electroporated with the two constructs and cell clones were derived after selection in $\mathrm{G} 418$ containing medium (400ug/ml). 24 of the resulting cell clones were analysed for expression of the luciferase gene after treatment with $10 \mu \mathrm{M}$ sulforaphane (or the solvent, DMSO) for $24 \mathrm{~h}$ (suppl. Fig. S4).

The absolute expression rates of the clones vary widely (by a factor of 10,000 fold). Treatment of the cell clones with sulforaphane for $24 \mathrm{~h}$ lead to an activation of 
luciferase expression in 10 of the 24 clones. In 7 of the clones the activation was around 5 fold; in the clone A4 the sulforaphane mediated activation was around 20 fold. The clone A4 (showing the highest amplitude of response to SFN) and the clone C1 (one of the two highest expressing clones) were selected for further experiments. Cells transfected with a construct carrying a mutation of the anti-oxidant response element which contains the binding site for the transcription factor Nrf2 [20] do not show a significant activation of the luciferase reporter gene (suppl. Fig. S4f). This is consistent with data obtained in a transient transfection assay. Stimulation with $10 \mu \mathrm{M}$ SFN activates expression of a luciferase reporter gene driven by the wildtype NQO1 promoter by 3 fold, whereas the mutant promoter does not support a reporter gene activation (suppl. Fig. S5). Interestingly a concentration of $10 \mu \mathrm{M}$ curcumin fails to activate the NQO1 promoter in a transient transfection assay but does activate expression of the endogenous NQO1 gene and a stably integrated reporter gene. This suggests that the activation by curcumin may require sequence elements in the NQO1 promoter which are not present in the reporter gene construct, or that some sequence elements in the promoter only become functional when the reporter construct is integrated into the genome and properly populated by histone structures. We have observed the latter phenomenon in the promoter of the $\beta$-casein (CSN2) gene [32].

\subsection{Validation of reporter cell lines}

The cell clones HepG2-C1 and HepG2-A4 were tested for their response to increasing concentrations of SFN and CUR (from 200nM to $20 \mu \mathrm{M}$ ) over a $24 \mathrm{~h}$ period (Fig. 2a and b). SFN induces significant increases in luciferase expression from a concentration of $0.7 \mu \mathrm{M}$ (Fig. 2a) with a maximum induction of 13-fold at a concentration of $28 \mu \mathrm{M}$. In contrast CUR concentrations from $7 \mu \mathrm{M}$ are required to induce a significant increase in luciferase expression (Fig. 2b). Concentrations above $30 \mu \mathrm{M}$ are cytotoxic within the $24 \mathrm{~h}$ incubation period for both treatments. Incubation of HepG2 C1 cells with different concentration of SFN over extended time periods demonstrates that maximum induction levels for all concentrations are achieved after a $48 \mathrm{~h}$ treatment (Fig. 2c) with a maximum induction of 18 -fold after a $48 \mathrm{~h}$ incubation at a concentration of $28 \mu \mathrm{M}$. Expression of the endogenous NQO1 and HMOX1 genes is increased in response to SFN and CUR treatment in cell clones HepG2-C1 and A4 (Fig. 2d and e). Indeed, HMOX1 expression in response to CUR in the cell clone A4 is significantly higher than in the parental cells $(p<0.05)$, suggesting that subclones of HepG2 cells can be more responsive to phytochemical treatment than the parental cell line. The induction of the endogenous phase II enzyme genes AKR1B10 and NQO1 in response to $10 \mu \mathrm{M}$ SFN treatment over a $96 \mathrm{~h}$ incubation period was also verified by Western blotting (Fig. 3a and b) and qPCR (Fig. 3c).

\subsection{Screening of natural product libraries}

The HepG2 C1 cell line was used to screen a library of flavonoids. The library components were diluted 1:1000 from their stock solutions (20mM) to give a final concentration $20 \mu \mathrm{M}$. The reporter cells were treated for $24 \mathrm{~h}$ after which cell viability and luciferase expression was measured. The mean of 3 independent experiments is shown in figure 4. Only two of the compounds showed a reduction of viability to less than $75 \%$ of control levels over the $24 \mathrm{~h}$ incubation period. Five compounds showed 
an induction of luciferase expression of more than 5-fold. Two compounds, MBC20 and $\mathrm{MBC} 37$ combined absence of toxicity (over the incubation period) with a high activation of the luciferase reporter gene. The compounds were selected for further analysis. As a first step the effects of $\mathrm{MBC} 20$ and $\mathrm{MBC} 37$ on cell viability and luciferase activation was assessed over a wider range of concentrations. Both MBC20 and MBC37 show a lower rate of cytotoxicity compared to SFN at higher concentration (above $30 \mu \mathrm{M}$ ) (Fig. 5a) and show a higher activation of the luciferase reporter gene at these concentrations (Fig. 5b). In addition, the effect of MBC20 and MBC37 was studied over extended incubation periods with regards to activation of the luciferase reporter gene (Fig. $\mathbf{5 c}$ and $\mathbf{d}$ ) and cell viability (Fig. 5 e and f). DMSO the solvent for both compounds only showed significant effects at very high concentrations which were never reached in the course of the normal experiments (data not shown). For both, MBC20 and MBC37, extended incubation periods resulted in increases in cytotoxicity but also in reporter gene activation. In the case of MBC37 luciferase reporter activation of $>90$ fold was observed with a nonsignificant decrease in cell viability to $83 \%$ of control cells.

The impact of MBC37 treatment on the expression of the endogenous phase II enzymes NQO1 and AKR1B10 was further assessed using Western blotting (Fig. 6a). Increasing amounts of both, NQO1 and AKR1B10 protein were found in HepG2-C1 cells treated with $20 \mu \mathrm{M} \mathrm{MBC} 37$ for $24 \mathrm{~h}, 48,72 \mathrm{~h}$ (Fig. $6 \mathrm{~b}$ ), reflecting the increases seen in reporter gene expression (Fig. $\mathbf{5 c}$ and d). The expression of genes encoding 3 phase II enzymes (NQO1, HMOX1 and AKR1B10) was significantly increased after a $24 \mathrm{~h}$ incubation period as assessed by qPCR (Fig. 6c). MBC37 had a marginally more pronounced effect on the expression of the NQO1 and HMOX1 genes (4.8-fold and 3.4-fold induction, respectively) relative to $\mathrm{MBC} 20$.

The reporter cell line HepG2-C1 was also used to screen the Phytoquest library (www.phytoquest.co.uk) obtained from Life Arc (London, UK). The library contains around 1200 compounds of natural origin. A total of 24 compounds were found to increase the expression of the reporter gene by more than 5 fold while having no significant effect on cell viability (suppl. Fig. S6). Some compounds in the phytoquest library generated much higher responses of luciferase reporter gene activation, but also displayed a much higher level of cytotoxicity. Most compounds which increased luciferase activity by more than 10 fold also reduced cell viability to $60 \%$ or less (suppl. Fig. S6b). Some compounds actually enhanced viability (as did some compounds of the flavonoid library, shown above in Fig. 4). Although most phytochemicals (especially flavonoids) attenuate cell proliferation, some have been shown to promote cell growth [33,34].

\section{Discussion}

We have generated a cell based assay system to identify natural chemicals which activate the environmental cell stress response (anti-oxidant response) and screened two natural product libraries for activators of this signalling pathway. In contrast to other assay systems [9,35-37], we decided to use a $1.1 \mathrm{~kb}$ promoter elements of a phase II response gene (NQO1) rather than an isolated anti-oxidant response 
element (ARE) in order to achieve a better representation of the numerous regulatory influences which interact to achieve an overall activation of ESR genes. However, we observed a marked reduction in overall reporter gene expression in cells stably transfected with a reporter construct carrying a mutation of the ARE suggesting that the ARE is also critical for promoter activity levels in a non-activated state. In addition, we used an insulator element derived from the chicken globin gene to buffer the reporter gene against the silencing influences of surrounding chromatin structures. The insulator sequence has been successfully by us and others to promote stable levels of transgene expression [21,38,39].

The response of luciferase reporter gene in the reporter cell line HepG2-C1 faithfully reflects the regulation of the endogenous NQO1 gene suggesting that most important regulatory elements are present in the promoter fragment controlling reporter gene expression. We find that the activation of the luciferase reporter gene is lower during a transient transfection than in the cell clones in which the reporter gene construct is stably integrated. This may be due to the overall structure of the transgene integration site which may favour higher reporter gene activation. Expression and inducibility of the reporter gene remained stable throughout the typical period in which the cell lines were used (passage 4 to 12 ) suggesting that the co-transfection of insulator elements was effective in preventing the silencing of the transgene by epigenetic mechanisms $[31,40]$.

The cell clones $\mathrm{C} 1$ and $\mathrm{A} 4$, which were selected for their amplitude of reporter gene activation also showed a higher activation of endogenous phase II genes in response to SFN treatment. This may suggest that the isolated cell clones carry genetic or epigenetic alteration which increase phytochemical uptake or reduce phytochemical excretion (e.g. via $A B C$ transporter proteins) $[41,42]$.

The overall proteomics analysis of changes in response to SFN or CUR treatment only yielded very few protein changes, many of which were not reflected at the level of RNA suggesting that at the concentrations used $(10 \mu \mathrm{M})$ and the time period of treatment $(24 \mathrm{~h})$ changes mainly affect proteins which are expressed at a low level and are not among the around 1000 detected by 2D gel electrophoresis. Aldo-ketoreductases (including the 3 family members identified in the analysis AK1C1, AK1C2 and AKR1B10) are known phase II enzymes which are readily activated by toxic insults of natural and pharmacological agents [43]. The promoters of these genes may provide alternative DNA sequences for the generation of sensitive reporter gene constructs.

Most chemicals activating the ESR induce a U-shaped response curve and are cytotoxic at higher concentrations [37]. This response can be found for endogenous and reporter genes alike. The screening process of the $\mathrm{MBC}$ library and the phytoquest library allowed the assessment of both, cell viability and reporter gene activation. The two compounds isolated from the MBC library (MBC20 and MBC37) combined a high activation rate (in the range of SFN) with a much lower rate of cytotoxicity (relative to SFN). Cell health and viability can be measured using a variety of methods, which all have their advantages and disadvantages [44]. The 
objective of this study was to identify chemical compounds which are able to activate the ESR without overtly compromising cell survival. The use of the most popular cell viability assay reagents (MTT and resazurin) provide a useful indicator in this regard but will have to be complemented by the analysis of other markers of cell health to fully characterise the effects of the phytochemicals identified in the screen. The chemicals identified in the screens of the MBC and phytoquest libraries represent a diverse range of chemistries and may provide leads to the development of compounds which combine low toxicity with strong activation of the ESR response. We are currently assessing the critical structures common to these compounds and their bioavailability. These compounds may provide useful lead structures to develop compounds with therapeutic benefit for age-related diseases.

Anti-oxidants are often indicated as beneficial food additives. However, the efficacy of these chemicals has recently been questioned. Firstly, they often (though not always) have poor bioavailability. Secondly they sometimes suppress the endogenous anti-oxidant/cell stress response in which phase I and phase II enzymes are activated $[45,46]$. Therefore, compounds which are mild activators of the endogenous cell stress/anti-oxidant response may provide more benefit than chemicals with direct anti-oxidant activity. However, some chemicals may possess both pro- and anti-oxidative properties through different moieties.

Activators of the environmental cell stress response are not without problematic side effects. The ESR is e.g. induced by numerous anti-cancer drugs. In fact, aldo-keto reductases are seen as markers of poor cancer prognosis [47]. However, under normal circumstances the health benefits will prevail. In mice cancer is the major cause of death. Therefore treatments which increase life-span in mice, which are consistently associated with an increase ESR response, will very likely prevent, rather than promote, cancer [48].

\section{Declaration of competing interest}

The authors declare that they have no conflict of interest.

\section{Acknowledgements}

This work was funded by The Scottish Government Rural and Environment Science and Analytical Services Division (RESAS), Scotland, United Kingdom and the Biotechnology and Biological Sciences Research Council (BBSRC, East-Bio Doctoral Training Partnership), United Kingdom. The funders had no role in the design of the study, the analysis and interpretation of the data, or the publication process. The authors wish to thank Prof. John Hayes, University of Dundee, for the NQO1luciferase construct and Prof. Gary Felsenfeld, NIH, Bethesda for the plasmid pJC131. 


\section{References}

[1] A.J. Hulbert, R. Pamplona, R. Buffenstein, W.A. Buttemer, Life and death: metabolic rate, membrane composition, and life span of animals., Physiol. Rev. 87 (2007) 1175-213. doi:10.1152/physrev.00047.2006.

[2] C. López-Otín, M.A. Blasco, L. Partridge, M. Serrano, G. Kroemer, The hallmarks of aging., Cell. 153 (2013) 1194-217. doi:10.1016/j.cell.2013.05.039.

[3] K.B. Beckman, B.N. Ames, The Free Radical Theory of Aging Matures, Physiol. Rev. 78 (1998) 547-581. doi:10.1152/physrev.1998.78.2.547.

[4] T. Finkel, N.J. Holbrook, Oxidants, oxidative stress and the biology of ageing, Nature. 408 (2000) 239-247. doi:10.1038/35041687.

[5] S. Fulda, A.M. Gorman, O. Hori, A. Samali, Cellular Stress Responses: Cell Survival and Cell Death, Int. J. Cell Biol. 2010 (2010) 1-23. doi:10.1155/2010/214074.

[6] H.K. Bryan, A. Olayanju, C.E. Goldring, B.K. Park, The Nrf2 cell defence pathway: Keap1-dependent and -independent mechanisms of regulation, Biochem. Pharmacol. 85 (2013) 705-717. doi:10.1016/J.BCP.2012.11.016.

[7] K. Itoh, K.I. Tong, M. Yamamoto, Molecular mechanism activating nrf2-keap1 pathway in regulation of adaptive response to electrophiles, Free Radic. Biol. Med. 36 (2004) 1208-1213. doi:10.1016/j.freeradbiomed.2004.02.075.

[8] K. Taguchi, M. Yamamoto, The KEAP1-NRF2 System in Cancer, Front. Oncol. 7 (2017) 85. doi:10.3389/fonc.2017.00085.

[9] A.-M.J.F. Boerboom, M. Vermeulen, H. van der Woude, B.I. Bremer, Y.Y. LeeHilz, E. Kampman, P.J. van Bladeren, I.M.C.M. Rietjens, J.M.M.J.G. Aarts, Newly constructed stable reporter cell lines for mechanistic studies on electrophile-responsive element-mediated gene expression reveal a role for flavonoid planarity, Biochem. Pharmacol. 72 (2006) 217-226. doi:10.1016/J.BCP.2006.04.002.

[10] A. Martín-Montalvo, J.M. Villalba, P. Navas, R. de Cabo, NRF2, cancer and calorie restriction, Oncogene. 30 (2011) 505-520. doi:10.1038/onc.2010.492.

[11] J.H. Suh, S. V. Shenvi, B.M. Dixon, H. Liu, A.K. Jaiswal, R.-M. Liu, T.M. Hagen, Decline in transcriptional activity of Nrf2 causes age-related loss of glutathione synthesis, which is reversible with lipoic acid, Proc. Natl. Acad. Sci. 101 (2004) 3381-3386. doi:10.1073/pnas.0400282101.

[12] G. Shen, C. Xu, R. Hu, M.R. Jain, S. Nair, W. Lin, C.S. Yang, J.Y. Chan, A.-N.T. Kong, Comparison of (-)-Epigallocatechin-3-Gallate Elicited Liver and Small Intestine Gene Expression Profiles Between C57BL/6J Mice and C57BL/6J/Nrf2 (-/-) Mice, Pharm. Res. 22 (2005) 1805-1820. doi:10.1007/s11095-005-75468.

[13] G. Shen, C. Xu, R. Hu, M.R. Jain, A. Gopalkrishnan, S. Nair, M.-T. Huang, J.Y. Chan, A.-N.T. Kong, Modulation of nuclear factor E2-related factor 2-mediated gene expression in mice liver and small intestine by cancer chemopreventive agent curcumin, Mol. Cancer Ther. 5 (2006) 39-51. doi:10.1158/15357163.MCT-05-0293.

[14] S. Nair, W. Li, A.-N.T. Kong, Natural dietary anti-cancer chemopreventive compounds: redox-mediated differential signaling mechanisms in cytoprotection of normal cells versus cytotoxicity in tumor cells, Acta 
Pharmacol. Sin. 28 (2007) 459-472. doi:10.1111/j.1745-7254.2007.00549.x.

[15] C.E. Guerrero-Beltrán, M. Calderón-Oliver, J. Pedraza-Chaverri, Y.I. Chirino, Protective effect of sulforaphane against oxidative stress: Recent advances, Exp. Toxicol. Pathol. 64 (2012) 503-508. doi:10.1016/j.etp.2010.11.005.

[16] A.T. Dinkova-Kostova, W.D. Holtzclaw, R.N. Cole, K. Itoh, N. Wakabayashi, Y. Katoh, M. Yamamoto, P. Talalay, Direct evidence that sulfhydryl groups of Keap1 are the sensors regulating induction of phase 2 enzymes that protect against carcinogens and oxidants, Proc. Natl. Acad. Sci. 99 (2002) 1190811913. doi:10.1073/pnas.172398899.

[17] R.K. Thimmulappa, K.H. Mai, S. Srisuma, T.W. Kensler, M. Yamamoto, S. Biswal, Identification of Nrf2-regulated Genes Induced by the Chemopreventive Agent Sulforaphane by Oligonucleotide Microarray, Cancer Res. 62 (2002) 5196-5203. http://cancerres.aacrjournals.org/content/62/18/5196.abstract.

[18] A.T. Dinkova-Kostova, P. Talalay, NAD(P)H:quinone acceptor oxidoreductase 1 (NQO1), a multifunctional antioxidant enzyme and exceptionally versatile cytoprotector, Arch. Biochem. Biophys. 501 (2010) 116-123. doi:10.1016/J.ABB.2010.03.019.

[19] C.J. Miller, S.S. Gounder, S. Kannan, K. Goutam, V.R. Muthusamy, M.A. Firpo, J.D. Symons, R. Paine, J.R. Hoidal, N.S. Rajasekaran, Disruption of Nrf2/ARE signaling impairs antioxidant mechanisms and promotes cell degradation pathways in aged skeletal muscle, Biochim. Biophys. Acta - Mol. Basis Dis. 1822 (2012) 1038-1050. doi:10.1016/j.bbadis.2012.02.007.

[20] P. Nioi, M. McMahon, K. Itoh, M. Yamamoto, J.D. Hayes, Identification of a novel Nrf2-regulated antioxidant response element (ARE) in the mouse $\mathrm{NAD}(\mathrm{P}) \mathrm{H}$ :quinone oxidoreductase 1 gene: reassessment of the ARE consensus sequence., Biochem. J. 374 (2003) 337-48. doi:10.1042/BJ20030754.

[21] D.A. Sorrell, C.J. Robinson, J.-A. Smith, A.F. Kolb, Recombinase mediated cassette exchange into genomic targets using an adenovirus vector, Nucleic Acids Res. 38 (2010) e123-e123. doi:10.1093/nar/gkq192.

[22] S. Matsukura, P.A. Jones, D. Takai, Establishment of conditional vectors for hairpin siRNA knockdowns, Nucleic Acids Res. 31 (2003) e77. http://www.ncbi.nlm.nih.gov/pubmed/12888529 (accessed August 23, 2018).

[23] M.M. Bradford, A rapid and sensitive method for the quantitation of microgram quantities of protein utilizing the principle of protein-dye binding, Anal. Biochem. 72 (1976) 248-254. doi:10.1016/0003-2697(76)90527-3.

[24] C.A. Maloney, S.M. Hay, M.D. Reid, G. Duncan, F. Nicol, K.D. Sinclair, W.D. Rees, A methyl-deficient diet fed to rats during the pre- and peri-conception periods of development modifies the hepatic proteome in the adult offspring, Genes Nutr. 8 (2013) 181-190. doi:10.1007/s12263-012-0314-6.

[25] S.J. Duthie, Y. Mavrommatis, G. Rucklidge, M. Reid, G. Duncan, M.P. Moyer, L.P. Pirie, C.S. Bestwick, The Response of Human Colonocytes to Folate Deficiency in Vitro: Functional and Proteomic Analyses, J. Proteome Res. 7 (2008) 3254-3266. doi:10.1021/pr700751y.

[26] B. de Roos, A. Geelen, K. Ross, G. Rucklidge, M. Reid, G. Duncan, M. Caslake, G. Horgan, I.A. Brouwer, Identification of potential serum biomarkers of inflammation and lipid modulation that are altered by fish oil 
supplementation in healthy volunteers, Proteomics. 8 (2008) 1965. http://dx.doi.org/10.1002/pmic.200700457.

[27] T.J. Snelling, R.J. Wallace, The rumen microbial metaproteome as revealed by SDS-PAGE, BMC Microbiol. 17 (2017). doi:10.1186/s12866-016-0917-y.

[28] M. Szymanowska, K.A.. Hendry, C. Robinson, A.F. Kolb, EMMPRIN (basigin/CD147) expression is not correlated with MMP activity during adult mouse mammary gland development., J. Cell. Biochem. 106 (2009) 52-62. doi:10.1002/jcb.21975.

[29] J. Ye, G. Coulouris, I. Zaretskaya, I. Cutcutache, S. Rozen, T.L. Madden, PrimerBLAST: a tool to design target-specific primers for polymerase chain reaction., BMC Bioinformatics. 13 (2012) 134. doi:10.1186/1471-2105-13-134.

[30] M.M. Rahman, G.P. Sykiotis, M. Nishimura, R. Bodmer, D. Bohmann, Declining signal dependence of Nrf2-MafS-regulated gene expression correlates with aging phenotypes., Aging Cell. 12 (2013) 554-62. doi:10.1111/acel.12078.

[31] M.C. Walters, S. Fiering, E.E. Bouhassira, D. Scalzo, S. Goeke, W. Magis, D. Garrick, E. Whitelaw, D.I. Martin, The chicken beta-globin 5'HS4 boundary element blocks enhancer-mediated suppression of silencing, Mol Cell Biol. 19 (1999) 3714-3726.

[32] C. Robinson, A.F. Kolb, Analysis of mammary specific gene locus regulation in differentiated cells derived by somatic cell fusion, Exp. Cell Res. 315 (2009) 508-522. doi:10.1016/j.yexcr.2008.10.029.

[33] S.E. Jung, Y.H. Kim, S. Cho, B.J. Kim, H.S. Lee, S. Hwang, G.B. Kim, Y.H. Kim, M.G. Pang, S. Lee, B.Y. Ryu, A Phytochemical Approach to Promotion of Selfrenewal in Murine Spermatogonial Stem Cell by Using Sedum Sarmentosum Extract, Sci. Rep. 7 (2017). doi:10.1038/s41598-017-11790-0.

[34] B. Saud, R. Malla, K. Shrestha, A Review on the effect of plant extract on mesenchymal stem cell proliferation and differentiation, Stem Cells Int. 2019 (2019). doi:10.1155/2019/7513404.

[35] G.T. Wondrak, C.M. Cabello, N.F. Villeneuve, S. Zhang, S. Ley, Y. Li, Z. Sun, D.D. Zhang, Cinnamoyl-based Nrf2-activators targeting human skin cell photooxidative stress, Free Radic. Biol. Med. 45 (2008) 385-395. doi:10.1016/J.FREERADBIOMED.2008.04.023.

[36] R. Emter, G. Ellis, A. Natsch, Performance of a novel keratinocyte-based reporter cell line to screen skin sensitizers in vitro, Toxicol. Appl. Pharmacol. 245 (2010) 281-290. doi:10.1016/J.TAAP.2010.03.009.

[37] W.M.A. Westerink, J.C.R. Stevenson, G.J. Horbach, W.G.E.J. Schoonen, The development of RAD51C, Cystatin A, p53 and Nrf2 luciferase-reporter assays in metabolically competent HepG2 cells for the assessment of mechanismbased genotoxicity and of oxidative stress in the early research phase of drug development, Mutat. Res. Toxicol. Environ. Mutagen. 696 (2010) 21-40. doi:10.1016/J.MRGENTOX.2009.12.007.

[38] D.W. Emery, The use of chromatin insulators to improve the expression and safety of integrating gene transfer vectors, Hum. Gene Ther. 22 (2011) 761774. doi:10.1089/hum.2010.233.

[39] N. Grandchamp, D. Henriot, S. Philippe, L. Amar, S. Ursulet, C. Serguera, J. Mallet, C. Sarkis, Influence of insulators on transgene expression from integrating and non-integrating lentiviral vectors, Genet. Vaccines Ther. 9 
(2011). doi:10.1186/1479-0556-9-1.

[40] R.A. McKnight, M. Spencer, R.J. Wall, L. Hennighausen, Severe position effects imposed on a $1 \mathrm{~kb}$ mouse whey acidic protein gene promoter are overcome by heterologous matrix attachment regions., Mol. Reprod. Dev. 44 (1996) 179-84. doi:10.1002/(SICI)1098-2795(199606)44:2<179::AID-MRD6>3.0.CO;2$\mathrm{K}$.

[41] Y. Li, J.L. Revalde, G. Reid, J.W. Paxton, Interactions of dietary phytochemicals with $A B C$ transporters: possible implications for drug disposition and multidrug resistance in cancer., Drug Metab. Rev. 42 (2010) 590-611. doi:10.3109/03602531003758690.

[42] Y. Li, J. Lu, J.W. Paxton, The role of ABC and SLC transporters in the pharmacokinetics of dietary and herbal phytochemicals and their interactions with xenobiotics., Curr. Drug Metab. 13 (2012) 624-39.

http://www.ncbi.nIm.nih.gov/pubmed/22475331 (accessed August 27, 2015).

[43] K.-A. Jung, B. Choi, C.-W. Nam, M. Song, S.-T. Kim, J.Y. Lee, M.-K. Kwak, Identification of aldo-keto reductases as NRF2-target marker genes in human cells, Toxicol. Lett. 218 (2013) 39.

http://www.sciencedirect.com/science/article/pii/S0378427413000027.

[44] T.L. Riss, R.A. Moravec, A.L. Niles, S. Duellman, H.A. Benink, T.J. Worzella, L. Minor, Cell Viability Assays, 2004.

http://www.ncbi.nlm.nih.gov/pubmed/23805433 (accessed December 31, 2019).

[45] M. Ristow, K. Zarse, How increased oxidative stress promotes longevity and metabolic health: The concept of mitochondrial hormesis (mitohormesis), Exp Gerontol. 45 (2010) 410-418. doi:10.1016/j.exger.2010.03.014.

[46] M. Ristow, K. Zarse, A. Oberbach, N. Klöting, M. Birringer, M. Kiehntopf, M. Stumvoll, C.R. Kahn, M. Blüher, Antioxidants prevent health-promoting effects of physical exercise in humans., Proc. Natl. Acad. Sci. U. S. A. 106 (2009) 866570. doi:10.1073/pnas.0903485106.

[47] J.D. Hayes, M. McMahon, NRF2 and KEAP1 mutations: permanent activation of an adaptive response in cancer., Trends Biochem. Sci. 34 (2009) 176-88. doi:10.1016/j.tibs.2008.12.008.

[48] M.J. Steinbaugh, L.Y. Sun, A. Bartke, R.A. Miller, Activation of genes involved in xenobiotic metabolism is a shared signature of mouse models with extended lifespan, Am. J. Physiol. - Endocrinol. Metab. 303 (2012) E488-E495. doi:10.1152/ajpendo.00110.2012. 
Figures

A<smiles>CS(=O)CCCCN=C=S</smiles>

C

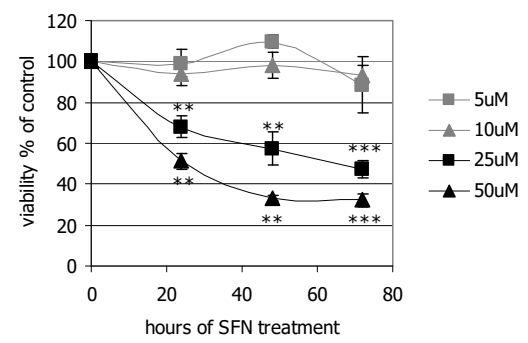

B

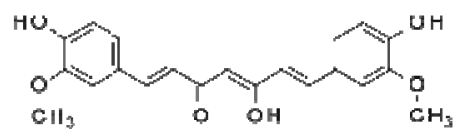

D

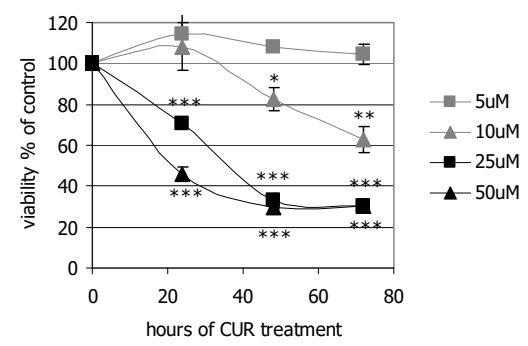

Figure 1: Chemical structures of sulforaphane (SFN) (panel A) and Curcumin (CUR) (panel B). Viability of HepG2 cells in response to treatment with different concentrations $(5 \mu \mathrm{M}, 10 \mu \mathrm{M}, 25 \mu \mathrm{M}, 50 \mu \mathrm{M})$ of the phytochemicals sulforaphane (SFN, panel C) and curcumin (CUR, panel D) for $24 \mathrm{~h}, 48 \mathrm{~h}$ and $72 \mathrm{~h}$. Viability was measured using the cell titer blue reagent and is shown as percentage of the viability of mock treated cells. Results were analysed by ANOVA $(n=4) .{ }^{*} p<0.5, * * p<0.01$, $* * * p<0.001$. 

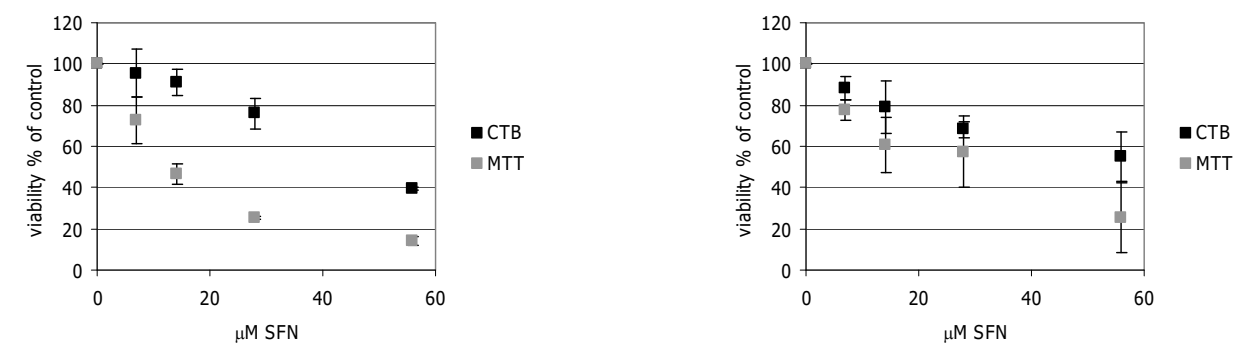

Supplementary Figure S1: Viability of HepG2 cells (Panel A) and Caco2 cells (Panel B) in the presence of $0,7,14,28$ and $56 \mu \mathrm{M}$ of SFN for $24 \mathrm{~h}$. Viability was measured using the cell titre blue assay (Promega) and the MTT assay (Abcam) $(n=2)$.

A

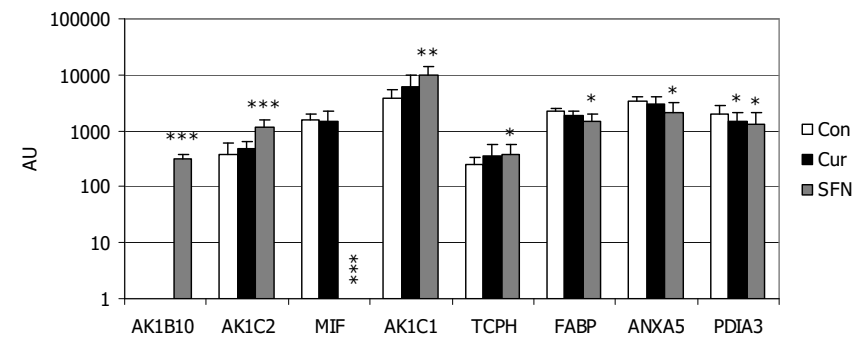

B

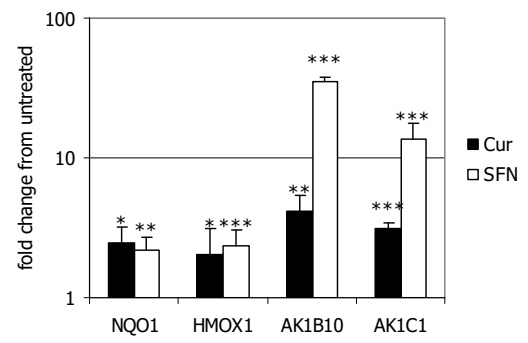

Supplementary Figure S2: Proteomics analysis of HepG2 cells treated with sulforaphane (SFN) or curcumin (CUR) at a concentration of $10 \mu \mathrm{M}$ for $24 \mathrm{~h}$. Panel A: Observed changes in the expression of HepG2 cell proteins in response to SFN and Curcumin treatment. Values represent arbitrary units (AU) measured by densitometric scanning. Panel B: Confirmation of observed changes in protein expression using quantitative PCR. Expression of the NQO1, HMOX1, AK1B10, and AK1C1 genes was measured in HepG2 cells in response to $24 \mathrm{~h}$ treatment with $10 \mu \mathrm{M}$ curcumin (CUR) or sulforaphane (SFN). Expression the genes was correlated with the expression of the reference gene $\beta$-actin. Fold changes of expression relative to control cells (treated with $0.1 \%$ DMSO) are shown. Results were analysed by ANOVA $(n=6) . * p<0.5, * * p<0.01, * * * p<0.001$. 
A

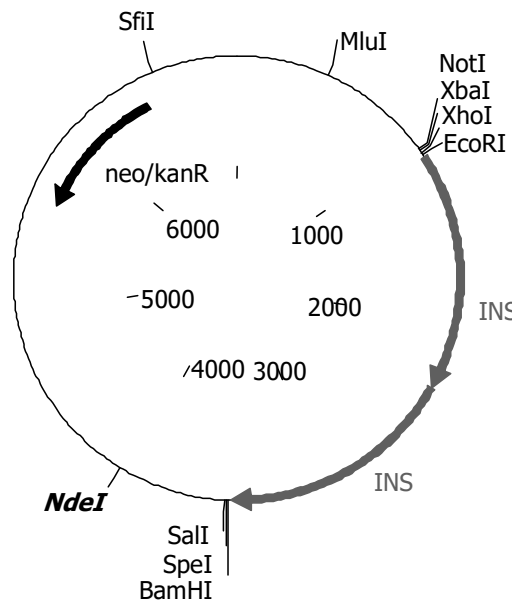

pBK-insulator 6915 bps
B

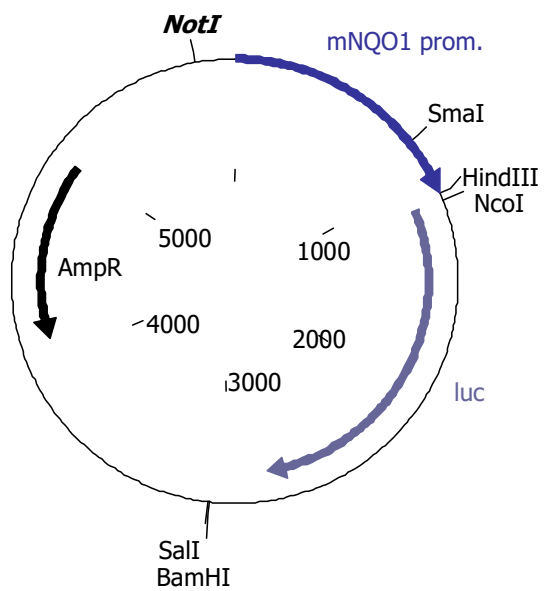

pGL3-mNQO1-Iuc

5844 bps

C

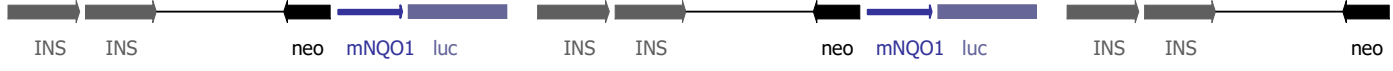

Supplementary Figure S3: Plasmid constructs used for the generation of the bioluminescent reporter cell lines. Panel A and B: Schematic representation of the plasmids pGL3-mNQO1-luc (pNQO1-luc) and pBK-INS2 which were stably transfected into HepG2 cells. The pNQO1-luc plasmid carries a $1.1 \mathrm{~kb}$ promoter fragment containing the antioxidant response element (ARE) of the mouse Nqo1 gene linked to a firefly luciferase reporter gene in the backbone of the plasmid vector $p G L 3$ (Promega). The pBK-INS2 plasmid contains two copies of the chicken $\beta$-globin insulator element in the backbone of the vector pBK-CMV (Stratagene) and a neomycin resistance gene. Panel C: Schematic representation of the potential structure of the transgene integration site. 
A

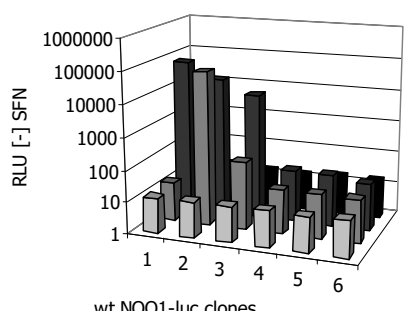

D

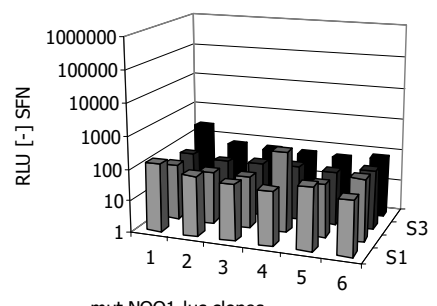

mut NQO1-luc clones
B

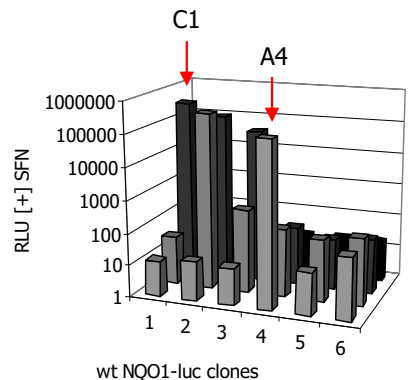

E

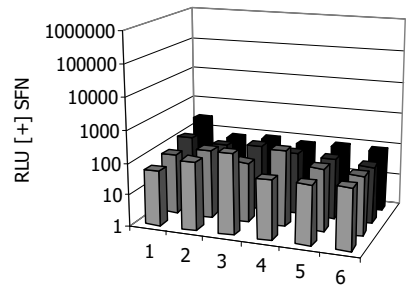

mut NQO1-luc clones
C

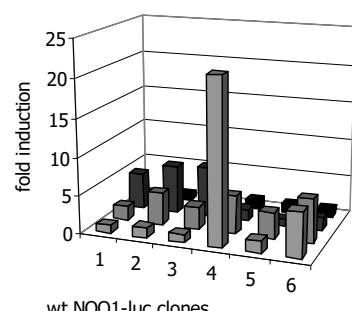

wt NQO1-luc clones

$\mathbf{F}$

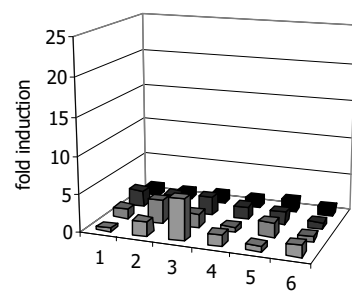

mut NQO1-luc clones

Supplementary Figure S4: Identification of HepG2 cells stably transfected with the reporter plasmids pNQO1-luc (panels A-C) and pNQO1-mut-luc (panels D-E). Both plasmids were co-transfected with the plasmid pBK-INS2 into HepG2 cells. Cells were selected in medium containing $400 \mathrm{ug} / \mathrm{ml} \mathrm{G} 418$. Stable cell clones were picked into a 24 well plate, expanded and treated with $10 \mu \mathrm{M}$ SFN for $24 \mathrm{~h}$ (or mock treated). Luciferase expression (relative light units: RLU) is shown for the untreated (panels $\mathbf{A}$ and $D$ ) and SFN treated cells (panels $B$ and E). The induction of luciferase expression in response to SFN treatment is shown in panels $\mathbf{C}$ and $\mathbf{F}$. The clones $A 4$ and $\mathrm{C} 1$ used for further analysis are indicated by arrows. Note that basal expression levels as well as inducible expression of the reporter gene is impaired in cells transfected with the pMQ01-mut construct (panels D-E). 
A

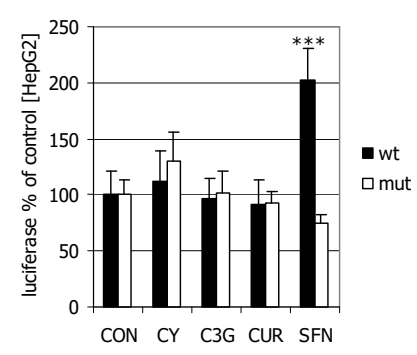

B

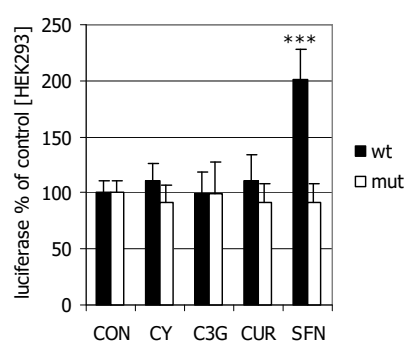

Supplementary Figure S5: Expression of a luciferase reporter gene after transient transfection into HepG2 cells (panel A) or HEK293 (panel B) cells. Cells were treated for $24 \mathrm{~h}$ with $10 \mu \mathrm{M}$ solutions of cyanidin (CY), cyanidin-3-gluoside (C3G), curcumin (CUR) or sulforaphane (SFN). Results are shown as \% expression of controls. Data were analysed by ANOVA ( $n=4) .{ }^{* * *} p<0.001$. 
A

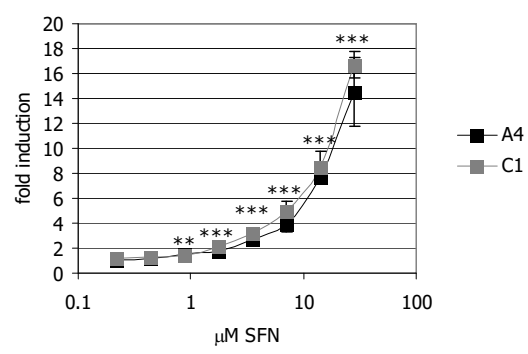

B

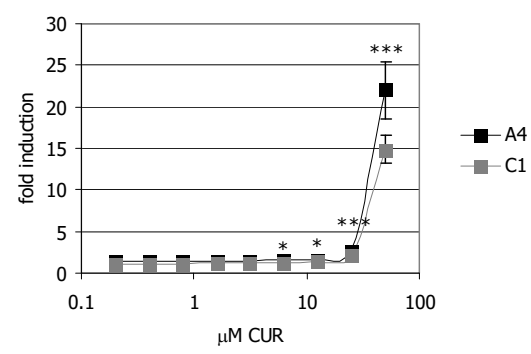

C

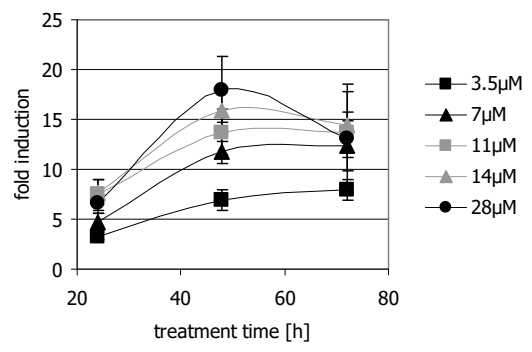

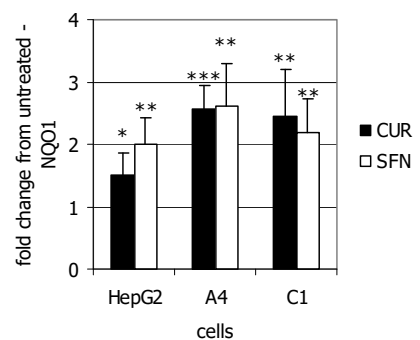

$\mathbf{E}$

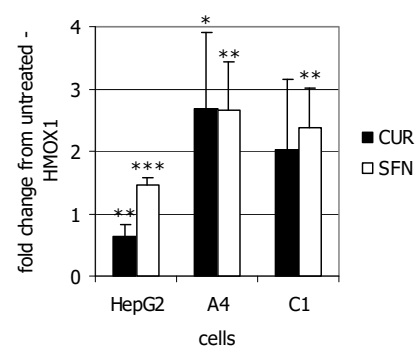

Figure 2: Validation of reporter cell lines. Panels A and B: Cell clones HepG2-C1 and A4 were exposed to different concentrations of the phytochemicals sulforaphane (SFN, panel A) and curcumin (CUR, panel B) for 24h. The relative induction of luciferase expression relative to untreated cells is shown. Statistical analysis was done by ANOVA $(n=4)$. Panel C: Treatment of HepG2-C1 cells with different concentrations of SFN over time. The induction of luciferase expression relative to untreated cells is shown. Statistical analysis was done by ANOVA $(n=9)$. All values are significantly different from untreated cells with $p<0.001$. Panels $\mathbf{D}$ and $\mathbf{E}$. Induction of the endogenous NQO1 and HMOX1 genes in response to treatment of cell clones HepG2-C1, HepG2-A4 and the parental HepG2 cells with sulforaphane (SFN, 10 $\mu$ M) and curcumin (CUR, 10 $\mu \mathrm{M})$. Expression of NQO1 and HMOX1 relative to the reference gene $\beta$-actin was assessed and is shown as fold change relative to mock treated cells. Results were analysed by ANOVA $(n=6) .{ }^{*} p<0.5, * * p<0.01, * * *$ $\mathrm{p}<0.001$. 
A

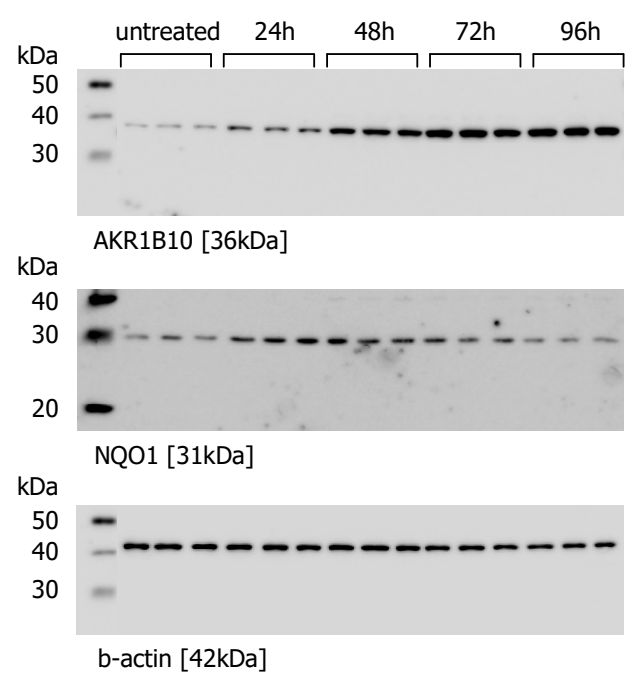

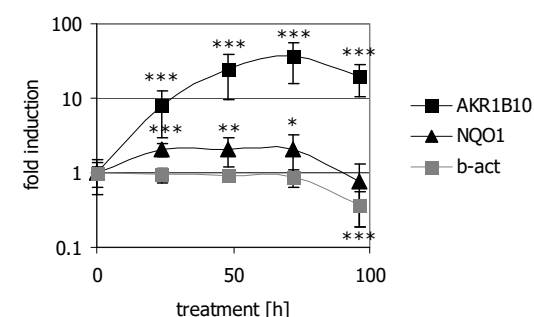

C

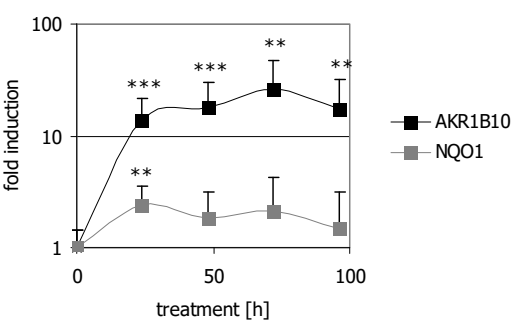

Figure 3: Protein and RNA expression in HepG2-C1 cells in response to $10 \mu \mathrm{M}$ SFN treatment over a 4 day period. Panel A: Western blot analysis of AK1B10, NQO1 and $\beta$-actin (reference protein) protein expression in HepG2-C1 cells in response to $10 \mu \mathrm{M}$ SFN treatment over a $24 \mathrm{~h}, 48 \mathrm{~h}, 72 \mathrm{~h}$ and $96 \mathrm{~h}$ period. Panel B: Quantification of NQO1 and AKR1B10 protein expression relative to the reference protein $\beta$-actin. Western blots were developed with chemiluminescent substrate and signals were quantified on an Aida Image Analyser. The results were analysed by ANOVA ( $n=3)$ Panel C: Expression of the phase II response genes AKR1B10 and NQO1 as determined by qPCR and correlated to the reference gene $\beta$-actin. Induction of the genes relative to mock treated cells is shown. Results were analysed by ANOVA $(n=6) . * p<0.5, * *$ $\mathrm{p}<0.01, * * * \mathrm{p}<0.001$. 
A

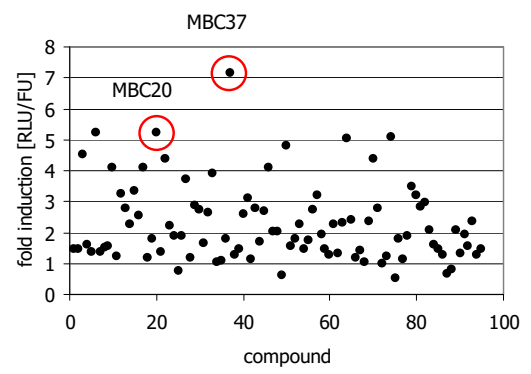

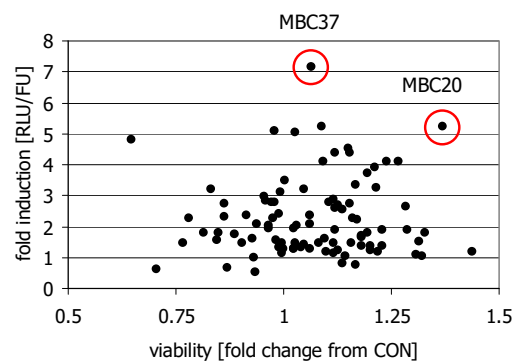

Figure 4: High throughput screening of a Marine Biodiscovery Centre (MBC) library of 96 natural compounds for their ability to induce NQO1-driven luciferase activity in HepG2 C1 cells. Cells were treated with the compounds for $24 \mathrm{~h}$ at a final concentration of $20 \mu \mathrm{M}$ compound $(0.1 \% \mathrm{v} / \mathrm{v}$ DMSO) $(\mathrm{n}=3)$. Panel A: Luciferase activity was normalised for cell viability (as measured by cell titre blue analysis) and values are expressed as fold change relative to vehicle control treated cells. Results are presented as the mean of three or four independent experiments. MBC20 and MBC37 were identified as inducing a 5.2-fold and 7.1-fold increase in luciferase activity, respectively. The positive control sulforaphane (at $10 \mu \mathrm{M}$ ) (not shown) induced the pNQO1-luc transgene by 8.3 -fold. Panel B: Correlation of cell viability and reporter gene activation. 
A

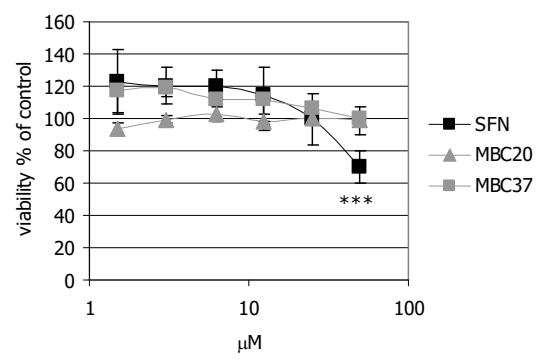

C

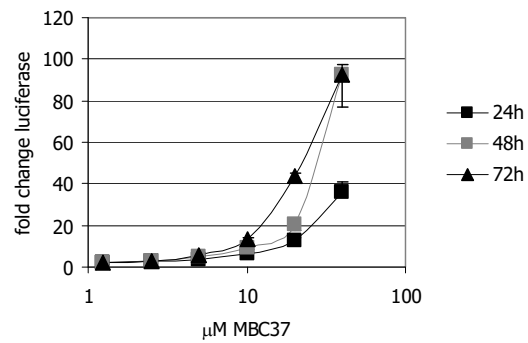

$\mathbf{E}$

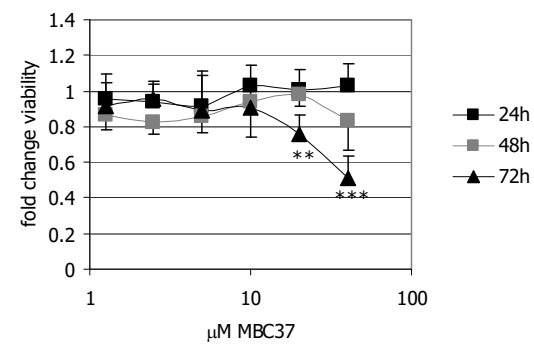

B

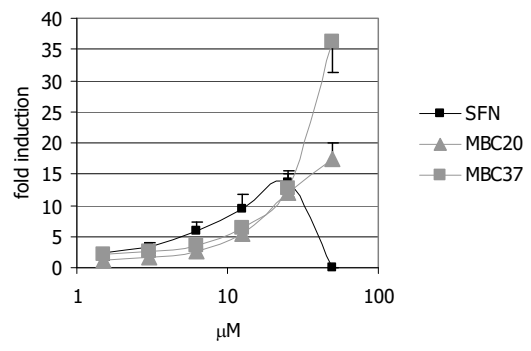

D

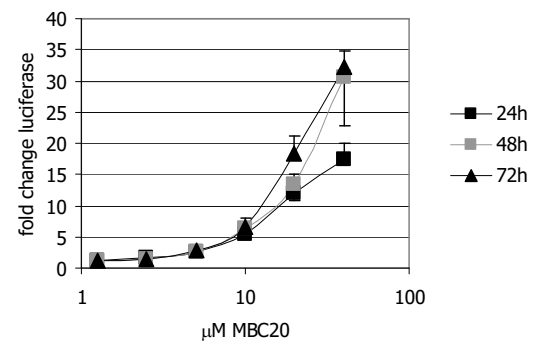

$\mathbf{F}$

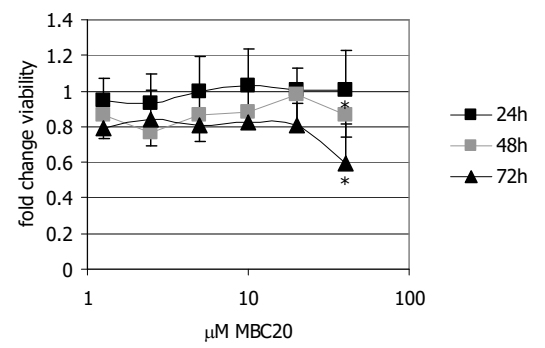

Figure 5, panel A: Viability of HepG2-C1 cells in response to treatment with different concentrations of SFN, MBC20, or MBC37 $(n=6)$ for $24 \mathrm{~h}$. Results were analysed by ANOVA. ${ }^{* * *} p<0.001$. Panel B: Phytochemical concentration dependent activation of reporter gene expression after $24 \mathrm{~h}$ of treatment $(n=6)$. P-values are $<0.001$ for all concentrations above $1.25 \mu \mathrm{M}$ for SFN and MBC37 and above $2.5 \mu \mathrm{M}$ for MBC20. Panel C: MBC37 concentration dependent activation of reporter gene expression after $24 \mathrm{~h}, 48 \mathrm{~h}$ and $72 \mathrm{~h}$ of treatment $(n=6)$. P-values are $<0.001$ for all concentrations (starting with $1.25 \mu \mathrm{M}$ ). Panel D: MBC20 concentration dependent activation of reporter gene expression (fold change luciferase) after $24 \mathrm{~h}, 48 \mathrm{~h}$ and $72 \mathrm{~h}$ of treatment $(n=6)$. P-values are $<0.001$ for all concentrations higher than $2.5 \mu \mathrm{M}$. Panel E: Viability of HepG2-C1 cells in response to treatment with different concentrations of MBC37 ( $\mathrm{n}=6$ ) for $24 \mathrm{~h}, 48 \mathrm{~h}$ and $72 \mathrm{~h}$ (fold change viability). ${ }^{* *}$ p-value $<0.01, * * * \mathrm{p}$ value <0.001. Panel F: Viability of HepG2-C1 cells in response to treatment with different concentrations of $\mathrm{MBC} 20(\mathrm{n}=6)$ for $24 \mathrm{~h}, 48 \mathrm{~h}$ and $72 \mathrm{~h} .{ }^{*} \mathrm{p}$-value $<0.05$. Error bars indicate standard deviation. 
A

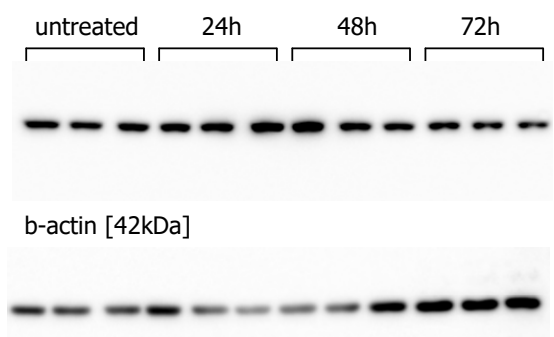

$\mathrm{NQO1}$ [31kDa]

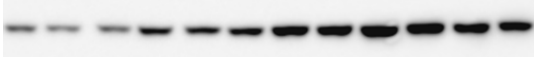

AKR1B10 [36kDa]

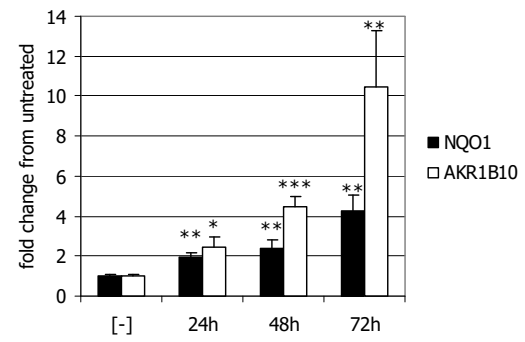

C

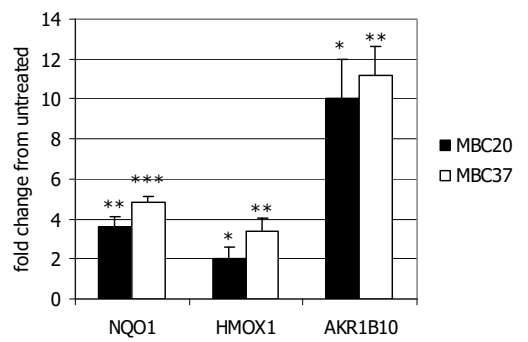

Figure 6: RNA and protein expression of phase II genes in HepG2-C1 cells in response to MBC20 and MBC37 treatment. Panel A: Time course of treatment of HepG2-C1 cells with $20 \mu \mathrm{M}$ MBC37. Western blot analysis of $\beta$-actin, NQO1 and AKR1B10 protein expression in response to treatment over $24 \mathrm{~h}, 48 \mathrm{~h}$ and $72 \mathrm{~h}(\mathrm{n}=3)$. Panel B: Quantification of NQO1 and AKR1B10 protein expression relative to the reference protein $\beta$-actin. Western blots were developed with chemiluminescent substrate and signals were quantified on an Aida Image Analyser. Panel C: Expression of the phase II response genes NQO1, HMOX1 and AKR1B10 in response to treatment with 20 $\mu \mathrm{M}$ $\mathrm{MBC} 20$ and $\mathrm{MBC} 37$ for $24 \mathrm{~h}$ as determined by qPCR and correlated to the reference gene $\beta$-actin. Gene activation relative to vehicle treated cells is shown $(n=6)$. Values significantly different from control are indicated by $* \mathrm{p}<0.05, * * \mathrm{p}<0.01$ or $* * *$ $\mathrm{p}<0.001$. 
A

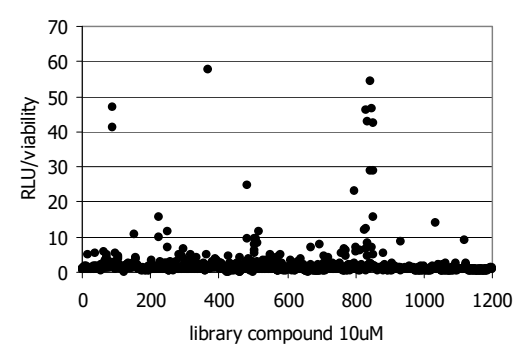

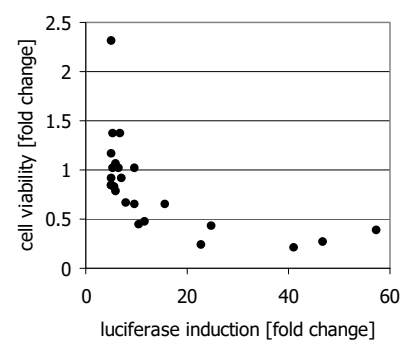

Supplementary Figure S6: High throughput screening of the phytoquest natural compound library provided by Life Arc. The 1200 compounds were screened for their ability to induce NQO1-driven luciferase activity in HepG2 C1 cells. Cells were treated for $24 \mathrm{~h}$ with compounds at a final concentration of $10 \mu \mathrm{M}$ (in $0.1 \% \mathrm{v} / \mathrm{v}$ DMSO). Panel A: Luciferase activity was normalised for cell viability (as measured by cell titre blue analysis) and values are expressed relative to vehicle control treated cells. Results are presented as the mean of two independent experiments. A total of 24 compounds generated a more than 5 fold induction of reporter gene expression. Panel B: Correlation of cell viability and reporter gene activation for the 24 compounds resulting in a higher than 5 fold induction of reporter gene expression. 
Table 1: Primer sequences used for amplification of cDNA by RT-qPCR

\begin{tabular}{llll}
\hline $\begin{array}{l}\text { gene and NCBI } \\
\text { reference } \\
\beta \text {-actin }\end{array}$ & $\mathbf{5}^{\prime}$-3' primer sequence & $\begin{array}{l}\text { annealing } \\
\text { temperature }\end{array}$ & $\begin{array}{l}\text { product } \\
\text { length }\end{array}$ \\
NM_001101.3 & F: GACGAGGCCCAGAGCAAGAGAG & $61^{\circ} \mathrm{C}$ & $387 \mathrm{bp}$ \\
$h A K R 1 B 10$ & F: GTCCCGGCCAGCCAGGTCCAG & & \\
NM_020299.4 & R: TGCTGACGATGAAGACTTC & $52^{\circ} \mathrm{C}$ & $286 \mathrm{bp}$ \\
$\begin{array}{l}\text { hHMOX1 } \\
\text { NM_002133.2 }\end{array}$ & $\begin{array}{l}\text { F: GCGGGCCAGCAACAAAGTGC } \\
\text { RNQO1 }\end{array}$ & $53^{\circ} \mathrm{C}$ & $393 \mathrm{bp}$ \\
NM_000903.2 & F: AGGACCCTTCATCCCTTCGCC & & \\
\end{tabular}

hAKR1B10, human Aldo-Keto Reductase Family 1, Member B10; hHMOX1, human heme oxygenase (decycling) 1; hNQO1, human $\mathrm{NAD}(\mathrm{P}) \mathrm{H}$ dehydrogenase, quinone 
Table 2: List of proteins significantly changed by treatment of HepG2 cells with SFN or CUR at a concentration of $10 \mu \mathrm{M}$ for $24 \mathrm{~h}$.

\begin{tabular}{|c|c|c|c|c|c|c|c|c|c|c|}
\hline spot & name & description & score & matches & sequences & coverage & exp. MW & obs. MW & SFN & CUR \\
\hline \#1 & $\mathrm{AK} 1 \mathrm{C} 1$ & Aldo-keto reductase family 1 member $\mathrm{C} 1$ & 605 & 49 & 14 & $51 \%$ & 37.22 & 37 kDa & $\uparrow$ & $\uparrow$ \\
\hline \#2 & ANXA5 & Annexin A5 & 338 & 28 & 14 & $45 \%$ & 35.97 & $35 \mathrm{kDa}$ & $\downarrow$ & $\downarrow$ \\
\hline \#3 & PDIA1 & Protein disulfide-isomerase 1 & 244 & 30 & 18 & $36 \%$ & 57.48 & $57 \mathrm{kDa}$ & $\downarrow$ & $\downarrow$ \\
\hline \#4 & AK1BA & Aldo-keto reductase family 1 member B10 & 200 & 14 & 10 & $34 \%$ & 36.22 & $36 \mathrm{kDa}$ & 个个 & $\uparrow$ \\
\hline \#5 & AK1C2 & Aldo-keto reductase family 1 member C2 & 189 & 14 & 7 & $18 \%$ & 37.11 & $37 \mathrm{kDa}$ & $\uparrow$ & $\uparrow$ \\
\hline \#6 & $\mathrm{TCPH}$ & T-complex protein 1 subunit eta & 188 & 14 & 12 & $26 \%$ & 59.84 & $59 \mathrm{kDa}$ & $\uparrow$ & $\uparrow$ \\
\hline \#7 & FABPL & Fatty acid-binding protein, liver & 175 & 18 & 5 & $33 \%$ & 14.25 & $14 \mathrm{kDa}$ & $\downarrow$ & $\downarrow$ \\
\hline \#8 & ERP29 & Endoplasmic reticulum resident protein 29 & 111 & 5 & 5 & $22 \%$ & 29.03 & $29 \mathrm{kDa}$ & $\uparrow$ & $\uparrow$ \\
\hline \#9 & MIF & Macrophage migration inhibitory factor & 107 & 6 & 2 & $17 \%$ & 12.63 & $12 \mathrm{kDa}$ & $\downarrow \downarrow$ & $\downarrow$ \\
\hline \#10 & TRFE & Serotransferrin & 93 & 7 & 7 & $10 \%$ & 79.29 & $79 \mathrm{kDa}$ & $\downarrow$ & $\downarrow$ \\
\hline \#11 & EZRI & Ezrin & 80 & 7 & 7 & $9 \%$ & 69.48 & $69 \mathrm{kDa}$ & $\downarrow$ & $\downarrow$ \\
\hline
\end{tabular}

The expected and observed molecular weights (MW) are shown for the mature proteins. The MS score is a measure of confidence of the detected protein species. A score higher than 39 is significant. The number of peptide sequence matches and the fraction of the total protein covered are indicated. The direction of change of protein abundance is indicated by the arrows ( $\uparrow:$ increase in abundance; $\downarrow:$ reduction in abundance) 